\title{
A trajetória histórica da visita domiciliária no Brasil: uma revisão bibliográfica
}

\section{The historical trajectory of the domiciliary visiting in Brazil: a bibliography revision}

\author{
La trajetoria histórica de la visita domiciliaria en Brasil: una revisión bibliográfica
}

\author{
Edirlei Machado dos Santos', Débora Isane Ratner Kirschbaum"
}

\section{RESUMO}

A visita domiciliária (VD) constitui-se instrumento importante para prática de enfermagem na saúde coletiva, especialmente, na Estratégia Saúde da Família. Estudo de revisão bibliográfica que tem objetivo contextualizar historicamente, a prática da VD em saúde no Brasil e sua articulação com diferentes modelos assistenciais adotados no país. Pesquisa foi realizada entre agosto/setembro de 2006, nas bases LILACS, SCIELO e BDENF utilizando descritores: visita domiciliar e assistência domiciliar. É possível depreender, da literatura estudada que VD, enquanto instrumento de trabalho nos serviços de saúde pública, esteve presente na prática dos serviços de assistência à saúde e de enfermagem em diferentes momentos históricos, embora sua finalidade e intensidade com que foi empregada como meio de trabalho, tenha mudado de acordo com o projeto político existente. $\mathrm{Na}$ atual conjuntura das políticas de saúde e dentro do modelo de reorganização do modelo assistencial a VD esta posta como possibilidade de concretização de ações de forma integral, haja vista que, este instrumento permite conhecer o cenário social em que cada indivíduo/família convive. Assim, este estudo permite refletir a forma como está se dando a realização da VD, considerando todo contexto histórico e social em que a mesma tem se desenvolvido no cenário dos serviços de saúde.

Palavras chave: Visita domiciliar; Assistência domiciliar; Enfermagem em saúde comunitária.

\footnotetext{
ABSTRACT

The domiciliary visiting (DV) represents an important instrument to nursing practice in collective health, especially in the Family's Health Strategy. It is about a bibliography revision that aims to contextualize historically the practice of DV in health in Brazil as well as its articulation with the different assistential models adopted in the country. This study was made between August/September of 2006, in the bases of LILACS, SCIELO and BDENF using:
}

domiciliary visiting and home nursing. It is possible to infer in the literature studied that DV, an instrument of work in the public health services, happened in the practice of health assistential services and nursing assistential services at different historical moments. Although its purpose and intensity used as means of work has changed according to the political project previously existent. In the present conjuncture of the health politics and according to the reorganization model of the assistential model, the DV is placed as a possibility of realization of actions in a whole way, since; this instrument allows knowing the social field where each individual/family lives. So, this study makes possible to reflect the way the DV is being done, considering the entire historical and social context in which it has been developed in the field of health services.

Key words: Home visit; Home nursing; Community health nursing.

\section{RESUMEN}

La visita domiciliaria (VD) se constituye en un instrumento importante para la práctica de la enfermería en la salud colectiva, especialmente en la Estrategia Salud de la Familia. Se trata de una revisión bibliográfica que tiene como objetivo contextualizar históricamente la práctica de la VD en salud en Brasil y su articulación con los distintos modelos asistenciales adoptados en el país. Esta pesquisa fue realizada entre Agosto/Septiembre de 2006, con base en LILACS, SciELO y BDENF

\footnotetext{
Trabalho extraído da introdução do projeto de pesquisa intitulado "A visita domiciliária sob a ótica do usuário" em desenvolvimento no Programa de Pós-Graduação - Mestrado em Enfermagem da Universidade Estadual de Campinas UNICAMP/SP.

' Enfermeiro, Especialista em Saúde Pública e Auditoria de Enfermagem, Docente do Curso de Graduação em Enfermagem das Faculdades Integradas de Santa Fé do Sul - FUNEC/SP, Mestrando em Enfermagem pela UNICAMP/SP.

"Enfermeira, Orientadora, Professora Doutora, Docente do Departamento de Enfermagem da Faculdade de Ciências Médicas (FCM) da Universidade Estadual de Campinas.
} 
utilizando: visita domiciliaria y asistencia domiciliaria. Es posible recoger de la literatura estudiada, que la VD, en cuanto instrumento de trabajo en los servicios de salud público a estuvo presente en la práctica de los servicios de asistencia a la salud y de enfermería en diferentes momentos históricos, aunque su finalidad y la intensidad con que fue empleada como medio de trabajo haya cambiado de acuerdo al proyecto político existente. En la actual coyuntura de las políticas de salud y dentro del modelo de reorganización del modelo asistencial, la VD está ideada como posibilidad

\section{NTRODUÇÃO}

A visita domiciliária, como instrumento de trabalho para a enfermagem, passou a ser ainda mais incrementada com a introdução do Programa de Saúde da Família (PSF), das propostas de atenção domiciliar e de reinserção social das pessoas com transtornos mentais no campo da atenção à saúde no Brasil, na última década. Observa-se uma intensificação da publicação de relatos de experiência de documentos oficiais ressaltando sua importância as vantagens que ela proporciona para o sucesso dos empreendimentos em saúde pública.

Todavia, os problemas decorrentes de seu emprego, como uma técnica que, mobiliza questões que envolvem, por um lado, aspectos culturais dos usuários/famílias e de outro a formação dos trabalhadores e seu preparo para adentrar no domicílio das famílias convergem para uma dualidade criada no domicílio, tornando-se este, ao mesmo tempo um espaço privado e público respectivamente, situação esta que, tanto nos primórdios da saúde pública, tanto quanto, nos projetos de medicina comunitária dos anos setenta foram foco de preocupação $^{(1-2)}$.

A visita domiciliária esteve presente no contexto histórico brasileiro, assumindo características diferentes de acordo com os diferentes cenários sociais, políticos e ideológicos pelos quais perpassou. Pode ser definida como "um conjunto de ações de saúde voltadas para o atendimento tanto educativo como assistencial"(3).

A visita domiciliária ganha destaque no Brasil a partir de sua incorporação aos serviços sanitários da década de 20 , voltada quase que de concretización de acciones de forma integral, teniendo en consideración, que este instrumento permite conocer el escenario social en que cada individuo/familia convive. De esta forma, este estudio permite reflejar la forma en cómo se está dando la realización de la VD, considerando todo el contexto histórico y social en que la misma se ha desarrollado en el escenario de los servicios de salud.

Palabras clave: Visita domiciliaria; Atención domiciliaria de salud; Enfermería en salud comunitaria.

exclusivamente para a eliminação das grandes epidemias de doenças infecto-contagiosas. Ganha espaço contundente no cenário atual, reflexo da reorganização do modelo assistencial em saúde proposta a partir da década de 90, com a implementação de programas voltados ao atendimento no domicílio ${ }^{(4)}$, especialmente, a Estratégia Saúde da Família, no ano de 1994.

Esta estratégia propõe uma nova dinâmica para a estruturação dos serviços de saúde, bem como sua relação com a comunidade e os diversos níveis de complexidade assistencial. Assume o compromisso de prestar assistência universal, integral, equânime, contínua e, acima de tudo, resolutiva à população, na unidade de saúde e no domicílio, sempre de acordo com suas reais necessidades, identificando os fatores de risco aos quais ela está exposta e neles intervindo de forma apropriada(5).

Com a utilização, em larga escala, da visita domiciliária, principalmente nos serviços de saúde coletiva, é fundamental a reflexão sobre este instrumento de assistência, principalmente no campo de enfermagem, para que seja possível o planejamento de uma assistência integral, que busque compreender cada indivíduo no contexto social em que está inserido.

Diante disso, alguns questionamentos guiaram o delineamento do presente estudo como: a visita domiciliária tem sido um objeto de estudo privilegiado na produção científica atual da área de enfermagem e de saúde coletiva? Como este aspecto é explorado, ou não, pelos autores? Há uma análise crítica da visita domiciliária como estratégia de intervenção que traga subsídios para uma discussão relacionada à visão que os usuários 
formulam acerca deste instrumento de trabalho? As características e finalidades da visita domiciliária contemporânea são semelhantes às que estas apresentavam em contextos históricos diferentes do atual? Ou elas se transformaram tendo em vista as articulações que existem entre uma estratégia e o modelo assistencial ao qual está vinculada?

Assim, propomos neste trabalho a realização de um artigo de revisão, cujo objeto foi a produção científica sobre a visita domiciliária, e como objetivo descrever o contexto histórico da prática da visita domiciliária em saúde no Brasil, a partir do que se tem produzido na literatura nacional.

\section{METODOLOGI A}

Trata-se de uma pesquisa bibliográfica, desenvolvida com base em material já elaborado, constituído essencialmente de livros e artigos científicos. A principal vantagem da pesquisa bibliográfica consiste em proporcionar ao investigador a cobertura de uma variedade de fenômenos muito mais ampla. Assim, esse tipo de pesquisa é indispensável entre outros para a realização de estudos históricos ${ }^{(6)}$.

$O$ estudo foi realizado nas bases de dados LILACS (Literatura Latino Americana e do Caribe em Ciências da Saúde), BDENF (Base de Dados da Enfermagem), SciELO (Scientific Electronic Library On line), DEDALUS da Universidade de São Paulo e ACERVUS da Universidade Estadual de Campinas. Foram também utilizados artigos científicos ou outras publicações que chegaram ao conhecimento do autor e que abordassem a temática a ser estudada. Os artigos que abordavam a temática foram selecionados, independente do ano de publicação por se tratar de um estudo cujo interesse era a perspectiva histórica sobre o assunto.

Nas bases de dados on-line, LILACS foram encontrados 94 artigos, na base SciELO 26 e na BDENF 39. Foram selecionados 7 artigos da base de dados LILACS que correspondia aos mesmos 7 selecionados na base de dados BDENF. Dos 26 artigos da base de dados SciELO nenhum foi selecionado.

O critério empregado para seleção dos artigos foi a leitura de seus respectivos resumos, buscando nestes o contexto histórico da visita domiciliária no Brasil e seus aspectos conceituais.

As demais referências, empregadas neste estudo, foram oriundas de busca nas bases de dados DEDALUS e ACERVUS, da Universidade de São Paulo (USP) e Universidade Estadual de Campinas (UNICAMP), respectivamente.

Os descritores utilizados para busca foram: visita domiciliar e assistência domiciliar. O período de coleta dos dados aconteceu durante os meses de agosto/setembro de 2006.

A análise do material teve inicio com a leitura dos trabalhos selecionados e foi guiada de forma a evidenciar a trajetória histórica da visita domiciliária no Brasil, procurando enfocar as diferentes maneiras com que este instrumento foi utilizado em um contexto histórico-social. Essa análise é apresentada a seguir, onde apresentamos os achados no material pesquisado articulado ao referencial teórico sobre o tema.

\section{Revisitando a pertinência da visita domiciliária como estratégia e sua delimitação}

A primeira questão que emerge da revisão de literatura realizada é a preocupação dos autores em demarcar a pertinência da visita domiciliaria como objeto de estudo.

A temática visita domiciliária merece reflexão, pois, ela é um dos instrumentos mais indicados para começar a trabalhar o indivíduo, a família e comunidade no processo de prestação da assistência à saúde, dentro do seu contexto social, desde que seja realizada mediante processo racional e com objetivos definidos $^{(7)}$.

Ao tomarmos como cerne a visita domiciliária, é necessário defini-la de acordo com as concepções existentes na literatura atual. Assim, as visitas domiciliares constituem um instrumento facilitador na abordagem de usuários e sua família. Por meio desse instrumento, é possível compreender a dinâmica familiar, verificando as possibilidades de envolvimento dessas, no processo de assistência oferecido ao usuário ${ }^{(8)}$.

Percebemos na literatura denominações diferentes, ora visita domiciliar, em outros momentos visita domiciliária. Diante disso, o vocábulo exato para denominar esse 
procedimento é visita domiciliária, porque, domiciliar é um verbo transitivo direto, significando dar domicílio a; recolher em domicílio; fixar residência ou fixar domicílio, enquanto que domiciliário é um adjetivo relativo a domicílio, feito no domicílio e cujo feminino é domiciliária ${ }^{(9)}$.

Diante do exposto, embora tenhamos optado por adotar o termo visita domiciliária ao nos referirmos a ela como instrumento do processo de trabalho em saúde, também decidimos preservar a nomenclatura empregada pelos diferentes autores aqui citados na discussão de seus trabalhos, qual seja visita domiciliar ou visita domiciliária.

É no contexto domiciliar que códigos e sinais emergem, nem sempre de modo nítido e que estes podem se caracterizar como sinais de resistência da família a intervenção de profissionais, por estarem invadindo sua intimidade. As famílias, mesmo demandando este modelo de assistência, parecem estar reivindicando certa garantia à sua intimidade ${ }^{(10)}$.

Desse modo, a afirmação anterior denota a presença do profissional no ambiente do domicílio, como invasão de privacidade da família, situação essa que pode estar associada à falta de um estabelecimento de vínculo profissional-família, um cenário de imposição de conhecimento do profissional sobre a família, muitas vezes não respeitando suas crenças e valores, tornando a família submissa ao profissional que presta essa assistência. Estes podem se caracterizar como alguns fatores determinantes deste processo de invasão de privacidade, o qual nos interessava resgatar como subsídio para reflexão acerca das relações entre o espaço público e o privado que estão em jogo no emprego desta técnica.

\section{O nascimento da visita domiciliária no Brasil}

A visita domiciliária no Brasil tem seu marco inicial, em artigo publicado em 15 de outubro de 1919 pelo "O Jornal", por meio do qual o Dr. J. P. Fontelle aborda a educação sanitária e a real necessidade de formação de enfermeiras visitadoras, sugerindo desta forma, a criação deste novo serviço. O surgimento desses serviços tinha como objetivo a prevenção(11).

No ano de 1921, por intermédio de Carlos Chagas, vem ao Rio de Janeiro um grupo de enfermeiras americanas, com a finalidade de desenvolver um curso para treinamento de visitadoras que deveriam prestar a assistência nos domicílios, levando em consideração, principalmente, um serviço de orientação às famílias no que se referia aos aspectos higiênicos de enfermidades como a tuberculose e ensinar sobre saúde infantil. Este curso se transformou alguns anos após, na Escola de Enfermagem Ana Nery(11).

Simultaneamente a este curso, foi criado em São Paulo, o Curso de Educadoras Sanitárias que tinha exatamente as mesmas finalidades $^{(11)}$.

A implantação da enfermagem moderna no Brasil se deu no bojo da reforma de Carlos Chagas. Neste período era realidade, a presença de epidemias e endemias que envolviam o Rio de Janeiro. Era visível a ineficácia dos serviços públicos e a indisposição dos médicos sanitaristas na realização de visitas domiciliares. Os médicos sanitaristas visualizavam o serviço de visitação domiciliária como pouco científico e inapropriado à sua posição social, tornando, a figura da enfermeira de saúde pública o cerne na execução desse modelo de assistência da época ${ }^{(4)}$.

No Brasil, a prestação de cuidados no domicílio não tem sido uma prática comum nas instituições de saúde pública e privada, posto que, no início do século, a atividade prioritária para o combate às grandes endemias eram as visitas domiciliares, onde o autoritarismo sanitário junto às famílias, empregado pelos agentes da época era muito explícito. Esta autora, neste mesmo estudo, agrupou as atividades da visitadora domiciliar para portadores de tuberculose em quatro funções, classificadas em ${ }^{(12)}$ :

- "função tática - penetrar na intimidade do tecido social, fazer a detecção precoce dos casos suspeitos de tuberculose, para tratamento ou isolamento e fazer registros minuciosos sobre as situações encontradas;

- função de representação - reforçar a ordem médica e a autoridade sanitária, 
lembrando a todos, por sua presença mesma, de seus deveres para com a saúde pública;

- função de persuasão - utilizar sua imagem ideal de mulher para fazer sentir às famílias o alto significado de sua visita e da magnanimidade do projeto oficial;

- função de controle - verificar o cumprimento das normas sanitárias de profilaxia da tuberculose"(12).

Diante disso, fica evidente a utilização da visita domiciliária enquanto estratégia adotada para desenvolver ações que fossem eficazes na prestação de cuidados em nível curativo para modificar a realidade epidemiológica da época. llustrando aqui a tuberculose como um dos problemas de saúde que assolavam o país e que atualmente, utiliza-se desse recurso como forma de garantia do tratamento e acompanhamento dos comunicantes intradomiciliares da doença. Outro fator marcante era a presença das autoridades sanitárias no domicílio das famílias independente de suas vontades, bem como fica latente, poder de dominação destas sobre as famílias, no cumprimento das práticas sanitárias por estes determinados.

\section{A década de $\mathbf{4 0}$ e a visita domiciliária}

$\mathrm{Na}$ década de 40, a visita domiciliária continua a ser empregada com a finalidade de fiscalizar os domicílios e objetivando mudar o perfil epidemiológico, caracterizado pelas grandes epidemias de doenças infectocontagiosas.

Neste período, foi criado o Serviço Especial de Saúde Pública (SESP) em 1942, serviço este, resultado de um convênio entre o governo norte americano e brasileiro, por ocasião da acentuada exploração da borracha como matéria prima, na região da Amazônia a ser utilizada na 2a ${ }^{a}$ Guerra Mundial ${ }^{(14)}$. Este serviço causou uma mudança no panorama sanitário de algumas regiões do país, pela sua eficiência e qualidade nos serviços prestados às pessoas em seus lares. Houve a partir daí uma expansão desse serviço para mais 12 estados do Brasil, sendo estes principalmente das regiões Norte e Nordeste ${ }^{(13)}$.

"O curso de visitadoras sanitárias foi instituído com o propósito de treinar pessoal para exercer atividades de saúde pública nos Postos de Higiene, estabelecidos e mantidos pelo SESP no Programa da Amazônia. Os primeiros Cursos foram realizados em Santarém e Itacoatiara, a fim de que as alunas pudessem receber 0 treinamento em condições semelhantes às das suas próprias comunidades"(14).

Além da formação profissional, as alunas recebiam também noções de educação doméstica, atuando nas atividades de copa, cozinha, rouparia, arrumação e limpeza em geral da casa, mercado, quintal, horta, criação de aves e acompanhando o trabalho dos serviçais $^{(14)}$.

Era uma característica da época, prestar esse tipo de assistência, para famílias com baixo poder aquisitivo, e que careciam de melhorias sanitárias. Assim, com o objetivo de modificar essa realidade o SESP, conclui que deveria intervir diretamente no interior do domicílio, sem ferir o respeito à família, por mais pobre que fosse garantindo dessa forma o mínimo de higiene da habitação. Os responsáveis pelo saneamento se preocuparam mais com o interior da casa, sugerindo o reboco das paredes, colocação de pisos, melhoria da cobertura da casa, das condições de iluminação e ventilação pelo aumento do pé direito e dimensões das janelas ${ }^{(14)}$.

A implementação dos serviços de enfermagem, toma a visita como estratégia de prestação de assistência às famílias.

A assistência de enfermagem domiciliária era caracterizada por uma sistematização mais ampla, pois além de seguir as orientações da época de São Vicente de Paula, preocupava-se com a sistematização do processo de visitação: com o preparo anterior à realização da visita; uso de técnicas adequadas desenvolvidas no domicílio; de roteiro para realização da visita; estabelecimento de prioridade para os doentes portadores de doenças transmissíveis que deveriam ser visitados separadamente ou em último lugar, para evitar infecções cruzadas; tendo preocupação com o tempo dispensado em cada visita ${ }^{(11)}$.

Nesse mesmo período, em 1947, foi criado - Serviço Especial de Saúde de Araraquara (SESA), que visava entre outros a prestação da assistência de enfermagem domiciliar ${ }^{(11)}$. 
Particularmente, trata-se de um dos métodos utilizados pela enfermagem para proporcionar uma assistência mais direcionada ao usuário e família.

Destarte, fica nítida que uma das funções do enfermeiro de saúde pública é certamente a visita domiciliária, o que demonstra que um serviço desta natureza que não desenvolva tal atividade se tornará paralisado, não apresentando desta maneira diferenças no atendimento prestado em ambulatórios hospitalares ${ }^{(15)}$.

\section{A visita domiciliária: da década de $\mathbf{5 0}$ até a criação do Sistema Único de Saúde}

No período compreendido entre as décadas de 50 a 70, a prática da visita domiciliária, enquanto método de prestação de assistência à saúde das pessoas, não aparece com destaque, haja vista que, que o contexto político, econômico e ideológico contribuía para este cenário, onde era realidade a presença de um sistema de saúde iníquo, considerando que saúde neste momento histórico ainda não era direito de todos nem ao menos dever do Estado ${ }^{(16)}$.

Esta foi entre outras, uma das razões para a criação do Ministério da Saúde no ano de 1953. No entanto, a criação desse Ministério embora tenha sido um marco importante na conjuntura histórica dos serviços de saúde no Brasil, não foi suficiente para garantir a facilidade de acesso aos serviços de saúde. Situação esta, que se acentuou com o Golpe Militar ocorrido na década de 60 , onde os serviços de saúde pública se tornaram tão deficientes que grandes epidemias voltaram a assolar o país, em detrimento do descaso e despreocupação por parte das autoridades que governavam o país ${ }^{(16)}$.

Com a inquietação por parte da sociedade e a necessidade de uma reformulação no panorama da saúde pública no Brasil, acontece a Reforma Sanitária, movimento constituído pelos diversos segmentos da sociedade na busca de um sistema de saúde público que atendesse os anseios no que concerne 0 processo saúde-doença, buscando garantir uma assistência universal, integral e equânime a toda população brasileira ${ }^{(16)}$.
Após a criação do atual sistema de saúde brasileiro, o Sistema Único de Saúde (SUS), nasce no início da década de 90 uma proposta de melhor organizar e assistir os usuários do SUS de modo mais próximo, o Programa de Agentes Comunitários de Saúde (PACS), criado no ano de 1991, tendo se firmado principalmente nas regiões Norte e Nordeste. Estes trabalhadores tinham como função prestar assistência aos usuários por meio da visita domiciliária(17).

Diante das afirmações anteriores, é possível perceber, empiricamente na atualidade, muitas características, dessa visita realizada no início do século $X X$, hoje empregada na atual conjuntura dos serviços públicos de saúde. Destacando-se o Programa da Saúde da Família (PSF).

Assim, no contexto do PSF, a visita domiciliária constitui-se de uma atividade utilizada com a finalidade de subsidiar a intervenção no processo saúde-doença de indivíduos, ou o planejamento de ações almejando à promoção de saúde da coletividade, se constituindo em um instrumento essencial, utilizado pelos integrantes das equipes de saúde para conhecer as condições de vida e saúde das famílias sob sua responsabilidade ${ }^{(18)}$.

A visita domiciliária, tomada no contexto do PSF, para a prestação de assistência no domicílio pode ser considerada fundamental, pois os trabalhadores da equipe de saúde da família no espaço domiciliar têm no espaço domiciliar uma possibilidade privilegiada para o desenvolvimento do diálogo e produção de saberes, salientando que o eixo estruturante dos serviços da atenção básica, especificamente o PSF são as ações educativas em saúde, que podem ser desenvolvidas, por meio do conhecimento construído na relação trabalhadores/usuários dos serviços de saúde ${ }^{(19)}$.

Nesta perspectiva, a visita domiciliária constitui-se com recurso fundamental para a prestação de assistência ao usuário/família, principalmente as ações educativas em saúde voltadas para as doenças crônico-degenerativas como a hipertensão arterial, que acomete um contingente considerável da população. Assim, a visita/assistência no domicílio são 
fundamentais ao considerar as peculariedades individuais e contextuais na relação usuário/profissional/família(20).

A visita domiciliária não é uma prática exclusiva da enfermagem, no entanto, esta desde seus primórdios se utilizou deste instrumento, quer fosse para prestar um atendimento com enfoque religioso, social, ou como forma de desenvolver ações de prevenção de doenças e promoção da saúde.

\section{CONSI DERAÇÕES FI NAIS}

Por meio da revisão da literatura especializada podemos concluir que a visita domiciliária originou-se na da década de $20 \mathrm{com}$ finalidades e características específicas e articulada ao modelo assistencial hegemônico naquela época. Esteve presente ao longo do período enfocado, permitindo-nos afirmar que, mesmo sendo empregada com enfoques diferentes e em maior ou menor escala essa não desapareceu totalmente do cenário brasileiro dos serviços de saúde pública.

A visita domiciliária, especificamente no cenário dos serviços de saúde no Brasil, atualmente vem sendo empregada em larga escala, enquanto instrumento de trabalho dos trabalhadores que constituem a equipe PSF.

Este programa, segundo pressupostos do Ministério da Saúde, caracteriza-se numa estratégia de reorganização dos serviços de assistência à saúde da população em nível primário, ou seja, na atenção básica, buscando por meio da sua implementação e efetivação garantir um acesso universal, eqüitativo e integral aos usuários do atual sistema de saúde brasileiro.

Considerando as colocações anteriores, acreditamos ser esta entre outras uma estratégia para consolidação do Sistema único de Saúde (SUS).

Desse modo, esse processo nos causa certa inquietação, pois ao utilizar a visita como instrumento, o processo de adentrar o domicílio dos usuários requer preparo, habilidades de comunicação, ética profissional, conhecimento dos mecanismos para prover à família uma assistência de cunho educativo, pautados em ações de prevenção e principalmente de promoção à saúde da população, assim como, maiores esclarecimentos acerca das relações entre espaço público e privado concebidos por usuários e profissionais de saúde de modo não necessariamente coincidente, trazendo conseqüências importantes para a implementação das práticas de saúde coletiva no país.

Neste cenário, fica evidente a prática da visita domiciliária nos serviços de saúde pública do Brasil. Cabe aqui refletirmos se esse trabalhador de saúde que adentra o ambiente (domicílio) do outro (usuário/família) tem preparo para realizá-lo, tomando como protagonista nesse processo o Agente Comunitário de Saúde (ACS).

Embora não fosse pretensão deste estudo discutir as competências do ACS, percebemos a necessidade de estudos que busquem caracterizar a concepção das famílias sobre a visita domiciliária realizada por trabalhadores do PSF, especificamente o ACS.

\section{REFERÊNCI AS}

1. Donângelo MC. Saúde e sociedade. São Paulo: Duas Cidades, 1979.

2. Costa NR. Lutas urbanas e controle sanitário: origem das políticas de saúde no Brasil. Petrópolis: Vozes, 1985.

3. Mattos TM. Visita domiciliária. In: Kawamoto EE, Santos MCH, Mattos TM. Enfermagem comunitária. São Paulo: Editora Pedagógica e Universitária; 1995. p. 35-9.

4. Fallante BSC, Barreira IA. Significados da visita domiciliar realizada pelas enfermeiras de saúde pública nas décadas de 20 e 30 . Escola Anna Nery. Rev Enferm. 1998;2(3):72-86.

5. Sousa MF. A enfermagem reconstruindo sua prática: mais que uma conquista no PSF. R. Bras. Enferm. 2000;53 (especial):25-30.

6. Gil AC. Como classificar as pesquisas? In: Gil, AC. Como elaborar projetos de pesquisa. 4a edição. São Paulo: Atlas, 2002. p. 41-58.

7. Mazza MPR. A visita domiciliária como instrumento de assistência de saúde. Rev. Bras. Cresc. Des. Hum. 1994;4(2):60-8.

8. Reinaldo AMS, Rocha RM. Visita domiciliar de enfermagem em saúde mental: idéias para hoje e amanhã. Revista Eletrônica de Enfermagem [Internet]. 2002 [cited 2007 feb 20];4(2):3641. Available from: http://www.fen.ufg. br/revista/revista4_2/pdf/vi sita.pdf. 
9. Egry EY, Fonseca RMGS. A família, a visita domiciliária e a enfermagem: revisitando o processo de trabalho da enfermagem em saúde coletiva. Rev. Esc Enf. USP. 2000;34(3):233239.

10. Alonso ILK. Luzes e sombras no ritual do encontro entre o universo profissional e o mundo da intimidade familiar: a intervenção profissional na saúde da família em âmbito domiciliar [tese]. [Florianópolis]: Universidade Federal de Santa Catarina/UFSC; 2003.

11. Augusto I, Franco LHRO. Aspectos históricos da assistência de enfermagem domiciliar. Laes Haes. 1980; 1(5): 50-52.

12. Barreira IA. A enfermeira Ana Néri no país do futuro: a aventura de luta contra a tuberculose [tese]. [Rio de Janeiro]: Escola de Enfermagem Anna Nery/UFRJ; 1992.

13. Bastos NCB. Educação sanitária: fundamentos, objetivos e métodos. In: Bastos NCB. Fundamentos metodológicos da educação sanitária. Rio de Janeiro: Fundação Serviço Especial de Saúde Pública; 1963. p. 367-498.

14. Bastos NCB. Treinamento de pessoal de saúde pública: 23 anos de experiência da FSESP, 1942-1965. Rio de Janeiro; 1966.

15. Costa J. Visitação domiciliária: base para o ensino de enfermagem na comunidade. Enf Novas Dimens. 1977;3(2):78-82.

16. Corbo AD, Morosini MVGC. Saúde da família: história recente da reorganização da atenção à saúde. In: Escola Politécnica de Saúde Joaquim Venâncio (Org.). Textos de apoio em políticas de saúde. Rio de Janeiro: Fiocruz; 2005. p. 157-181.

17. Rosa WAG, Labate RC. Programa Saúde da Família: a construção de um novo modelo de assistência. Rev. Latino-am Enfermagem. 2005; 13(6): 1027-1034.

18. Takahashi RF, Oliveira MAC. A visita domiciliária no contexto da saúde da família. In: Brasil IDS. Manual de Enfermagem. Universidade de São Paulo, Brasília: Ministério da Saúde; 2001. p. 43-46

19. Peres EM, Poz MRD, Grande NR. Visita domiciliar: espaço privilegiado para diálogo e produção de saberes. Rev. Enferm UERJ. 2006; 14(2): 208- 13.

20. Mantovani MF, Mottin JV, Rodrigues J. Visita domiciliar de enfermagem com atividades no tratamento da pressão arterial. Online Brazilian
Journal of Nursing. 2007 [cited 2007 feb 20];6(1). Available from: http://www.uff. br/objnursing/index.php/nursing /article/view/757/171.

Artigo recebido em 04.03.07

Aprovado para publicação em 31.03.08 